\title{
Public-Private Partnership in Health Care and Its Impact on Health Outcomes: Evidence from Ruharo Mission Hospital in Uganda
}

\author{
Justus Asasira $^{1}$, Frank Ahimbisibwe ${ }^{1}$ \\ ${ }^{1}$ Faculty of Interdisciplinary Studies, Mbarara University of Science and Technology, Uganda \\ Correspondence: Justus Asasira Faculty of Interdisciplinary Studies, Mbarara University of Science and Technology, \\ Uganda. E-mail: jasasira@must.ac.ug
}

Received: October 18, 2018

doi:10.11114/ijsss.v6i12.3911

\author{
Accepted: December 7, 2018 Available online: December 27, 2018
}

URL: https://doi.org/10.11114/ijsss.v6i12.3911

\begin{abstract}
Background: Uganda's government has embraced private provision of social services including health care. The involvement of private providers is an indicator that the public facilities are not sufficient enough to meet the high demands of the ever-increasing population. This has been done through partnership arrangements. This paper discusses the impact of Public-Private Partnership (PPP) in health care outcomes of the local population and opportunities for improving health outcomes, challenges facing private providers in a low income setting.
\end{abstract}

Methodology: Data were collected using qualitative methods in January 2017 through interview (using semi-structured questions) at Ruharo Mission Hospital (RMH) administration, health workers, district health office and used a structured questionnaire for patients/clients. This was a nascent study, with a sample size of 22 respondents. The hospital has three departments; Organized Useful Rehabilitation Services (OURS), General Medical Services (GMS) and Eye Department (ED). All the departments of the hospital were represented in this study.

Results: The hospital is a Church of Uganda project and runs a budget of 5 billion shillings $(\$ 1,351,351.4)$ annually, had multiple sources of funding including PHC funding annually and that, health services were delivered adequately to clients. Much as some services were accessed at no costs, other services like eye treatment were found expensive on the side of clients. The hospital's hybrid mode of delivering health services through outreaches and facility-based services was cherished, however it had no ambulance and relied only on a hospital van.

Conclusions and Recommendations: Our study concluded that if private providers are supported under the partnership arrangement, they can adequately deliver services to the clients and decongest the public facilities. We recommend that the government devote funds to support the hospital through employing more sub-seconded staff, procuring medicines, and ambulances to enable it to subsidize services especially eye treatment and other services not supported under the partnership.

Keywords: PPP, health care, funding, enablers and challenges

\section{Background}

Uganda's health sector is facing many challenges that include poorly remunerated and demotivated health workers, low motivation to enable retention of health specialists, underfunding of referral and sub-district hospitals, drug leakage, corruption, poor servicing of donated equipment, challenges of deployment and efficient supervision of decentralized human resource for health (Parliamentary Committee on health, 2012). According to Medicines Transparency Alliance (MeTA) Mbarara district is among the districts where healthcare delivery in public units has deteriorated. Accordingly, $32 \%$ of the patients visiting public units do not get all prescribed drugs, after a few days, only $2 \%$ return to the unit to check if drugs are available and the rest go to private health facilities. Using weighted average, satisfaction was rated at $47 \%$ but it was lower at health centre II's although medicines were available indicated by $80 \%$ (MeTA, 2014). Most of them find their way to private clinics hence high cost of healthcare, and this encroaches on their low incomes. What remains undocumented is whether the private providers satisfy the needs of the population in terms of health services delivered. On the economic aspect is whether their services are generally affordable to the users and how else the providers raise funds to sustain service delivery.

The government of Uganda adopted a policy of Public-Private Partnership in 2010 as a tool for provision of improved 
public services and public infrastructure based on principle of better value for money, appropriate risk transfer and management and taking advantage of private sector innovations (Mbarara District Development Plan 2015/16-2019/2020)

Health care services in Uganda have been decentralized and the health system works better through referrals. The household are served by community health workers (Village Health Teams-VHTs, communities/villages are served by the lowest level that is a health centre II, several villages (more than 2 parishes) are served by a health centre III, relatively complicated cases are referred to a health centre IV or hospital with theatre services such as minor surgeries, cesarean services and with an inpatient department. This is referral facility, known as Health Sub District (HSD) and can be a public or Non-Governmental Organization (NGO). Cases beyond this referral facility are further referred to health district services headquarter, then onwards to regional referral hospitals, national referral hospital and the destination is Ministry of Health Headquarters depending on the severity of the illness (Kamwesiga, 2011, Ministry of Health, 2010).

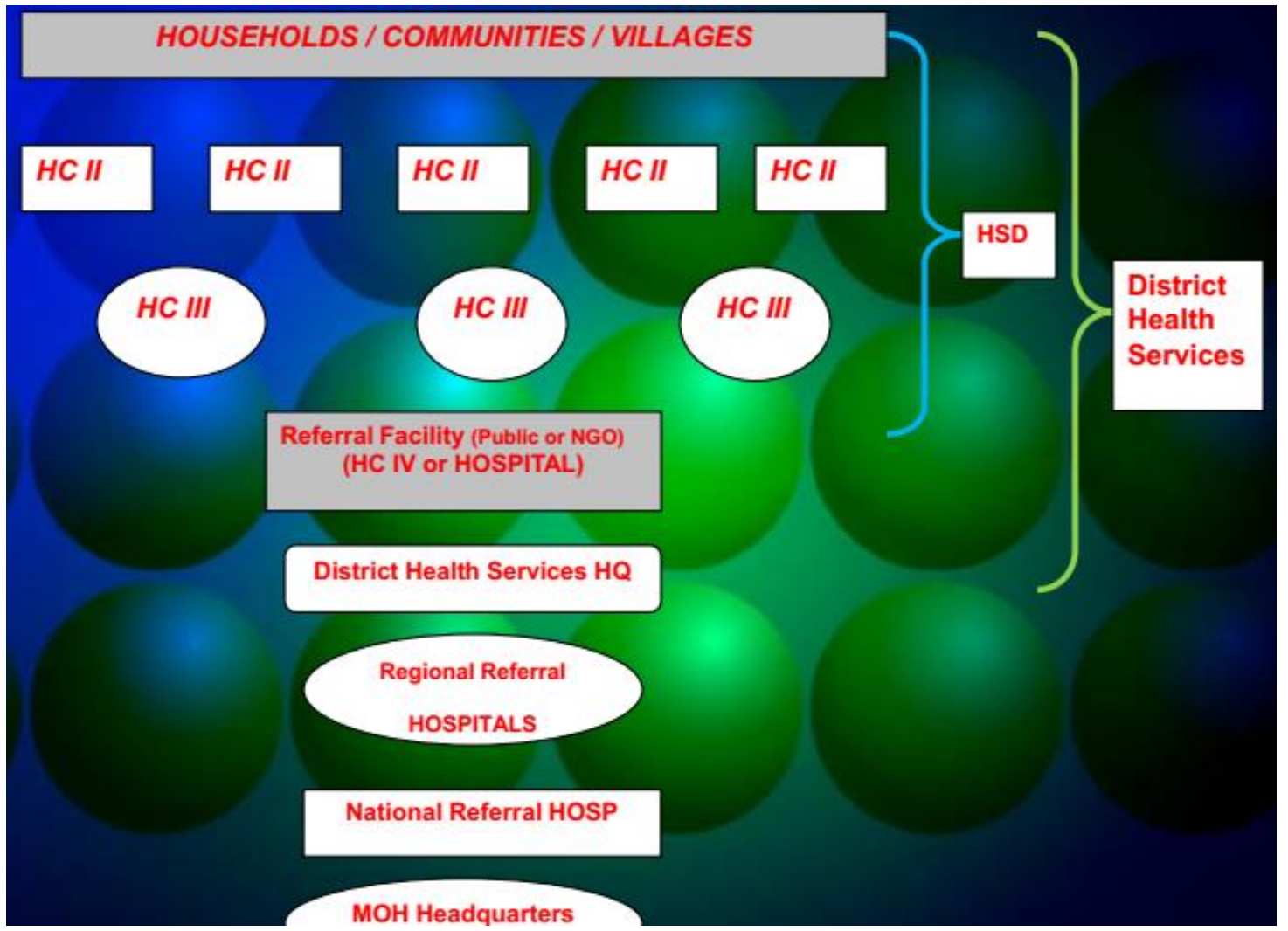

Source: Adapted Kamwesiga (2011)

Village health teams/community medicine distributors: The first contact for someone living in a rural area is a drug distributor or a member of the Village Health Team (VHT). Each village is supposed to have these volunteers (they are not paid for the work that they do) however they own bicycles to help them execute their duties including mobilization during immunization programmes. At times they have no medicine but they can advise and refer the patient to a health centre depending on the severity of their illness.

Health centre II: According to the Ugandan government health policy, every parish is supposed to have one of these health centres. A health centre II facility is meant to serve about 2000 people (in a given locality), should be able to treat common diseases like malaria. It is led by an enrolled nurse, working with a midwife and runs an outpatient clinic treating common diseases and offering antenatal care.

Health centre III: This is found in every sub-county in Uganda. These centres should have 18 staff led by a senior clinical officer with a functioning laboratory.

Health centre IV/district hospital: This level of health facility serve a county. In addition to services found at health centre III, it should have a ward for men, women and children and should admit patients. It is led by a senior medical officer and another doctor with about other 40 staff. It should have a theatre to carry out emergency operations. 
Regional Referral Hospital (RRH): There are 12 regional referral hospitals which should have in addition to services offered at health centre IV specialized clinics such as those for mental and dentistry and consultant physicians.

National Referral and Teaching Hospital: At the top of the healthcare chain is a national referral hospital. This is where some of the best medical brains can be found working part-time at private clinics to supplement their meagre government salaries (National Health Care Waste Management plan, 2011/2012).

Studies have found that the public sector cannot on its own meet the ever increasing health demands of the growing population thus Public-Private Partnerships (PPP). A national PPP policy was put in place to address health gaps in the health care system. Government collaboration with the private sector has in the past involved various programmes (e.g. Malaria Control Programme, Global Fund) or addressed special needs within the private sector (such as government subsidies to private sector). The Government of Uganda is developing the National Policy on Public Private Partnership in Health (PPPH), in order to build a sustainable partnership with the private health sector and strengthen the health care delivery system. The government aims to provide an enabling environment for effective coordination of efforts among all partners, to increase efficiency in resource allocation, achieve equity in the distribution of available resources for health and effective access by all Ugandans (National Policy on Public Private Partnerships in Health, 2011).

There are over 10 public-private partners in healthcare delivery operating in Mbarara district which started in 2002 to date, other facilities are getting into the partnership a recent one being Devine Mercy Hospital 2016 (DHO's office, 2016). One of the notable private partners for this study is Ruharo Mission Hospital, a faith-based facility offering a wide range of services. The overall goal of this research was to understand the impact of public-private partnership in health care outcomes of the served population, opportunities for improving health outcomes challenges facing private providers.

\section{Methodology}

Data were collected mainly using qualitative methods in January and February 2017 through interview (using semi-structured questions) with hospital administration, district health office and mixed methods (both qualitative and quantitative) were used for patients and health workers. A structured questionnaire was used for patients/clients and health workers. The hospital has three departments: Organized Useful Rehabilitation Services (OURS), General Medical Services (GMS) and Eye Department (ED). This was a nascent study with a sample size of 22 respondents. The study respondents were purposively selected from all the departments and was composed of 10 clients, 6 health workers, 4 hospital administrative staff and 1 district health official and 1 diocesan health officer. The interviews with clients and health workers took about 40 minutes, for other respondents interviews took between 60 minutes to 80 minutes.

Ethical approval from Mbarara University Research Ethics Committee (MUREC No 02/09-16) was obtained prior to the interviews, all interviews required written informed consent and confidentiality of interviewee identity was maintained in analysis and write-up. The study was also approved by Mbarara District Health Office (DHO).

\section{Results}

\section{Demographic data of the respondents}

Overall, $59 \%$ of the respondents were males. In the clients' category, $60 \%$ of the clients interviewed were females and males accounted for $40 \%$. More than $70 \%$ of the clients were peasants only $10 \%$ students, $10 \%$ business/self-employed and $10 \%$ were village health workers (VHT).

Health workers, administrative staff, district health and diocesan officials, had high education levels that is $33.3 \%$ (4) with a post-graduate qualification, $16.6 \%$ (2) degree, $16.6 \%$ (2) diploma and $33.3 \%$ (4) certificate.

\section{Impact of Public-Private Partnerships on Health care outcomes}

The existence of Ruharo Mission Hospital (RMH) has increased access to health services in Mbarara Municipality and beyond. General health, eye related and rehabilitation services are all delivered at this hospital. The hospital serves an average of 200 clients daily. The hospital extends services beyond the facility through outreaches to schools during the term, immunization, health education and regular check-ups for dental and eye services. Some of the services are free of charge for example Antiretroviral Treatment (ART) as medicines are supplied to the hospital free of charge from medical access, family planning, immunization services and mosquito nets.

A hybrid mode of service delivery has been adopted by RMH through organizing outreaches every year to offer free services and reduce the cost of transport for the users. For example in December 2016, the hospital had outreaches in Ibanda district and Mugarusya parish in Kashari County in Mbarara district where the health workers treated people with eye related difficulties, and gave out free eye glasses. Under this arrangement, the clients did not meet any cost including transport since the services were not facility-based. The hospital as well organizes a free surgery week every year to freely treat patients with eye problems. Our findings concur with what has been reported in the media about outreach programs. Outreach programs have not only worked for eye patients in Ibanda and Mbarara, in Omoro county, 
Rotarians have worked with hospitals in Nagulu, Bukoto and Gulu to freely treat over 2,000 patients. The services offered included general clinic, malaria treatment, laboratory services, ear, nose, throat, eye and dental clinic and blood donation (The New Vision, May 1, 2017).

The study found that the average number of days a client spent on admission were 3 and for outpatient department, a client on average spent 81.6 minutes to get health services. The patients on admission that realized an improvement had spent more than one day. The ones who had no change had spent a few hours on admission and the one whose health status had not improved after 1 day of admission was waiting for an eye operation. Our findings are in agreement with a study by MeTA (2014) that found out that $58 \%$ of the respondents indicated that long waiting hours were the biggest cause of dissatisfaction although the study did not indicate how long patients were waiting. The findings are not different from a study done in Addis Ababa, Ethiopia by Tateke (2012) which found out that the mean waiting time at a private hospital was 80.1 minutes compared to 134.1 minutes spent in public hospitals and more than 3 days for inpatients. The duration spent at the private facility was enough for patients to interact with medical staff for consultation which according to Sajid (2007) supports that spending long time during physical examination and contribution is associated with a higher satisfaction level.

The few days (3 days) spent on admission motivated the clients to come back to the PPP facility seeking healthcare services since they were spending few days compared to a minimum of 5 days at a public health facility. This explains why most patients would visit a PPP hospitals the next time they got a health issue. The clients in OPD revealed that whenever there was a delay it was procedural and therefore complained less about time spent since they found the staff. The overall satisfaction of clients was found to be higher in PPP than in public health facilities. The patients were critical on the waiting hours, although the waiting time was lower compared to time waiting to receive services in public facilities; the study findings indicated that the low levels of staffing had an impact in terms of health care quality (Bowling, 2012). The patients being many posed a question on whether there was adequate attention amidst low staffing levels. The clients explained that they were for long time while waiting for results from the laboratory due to few lab attendants.

\section{The type of partnership of Ruharo Mission Hospital}

The type of partnership of this hospital was Design-Build-Finance-Operate (DBFO). The facility under such a partnership was either built by individuals or religious organizations. The individuals and religion organization operate this facility with minimal support from the government through support supervision and primary health care financing.

This facility regularly gets support from the government in terms of supervision form the health officials at the district and ministerial level. The aim of the supervision is to strengthen the healthcare system and identify other areas of partnership to support the government in achieving national health goals. Supervisions also aim at identifying the partners and their role at a given facility so that the government does not duplicate what is already being done. Since this facility is given support financially and is supplied with medicines, medical equipment, health records materials and other supplies, the supervision also ascertains whether these are put in proper use to improve healthcare. The medicines and other medical equipment are supplied by medical access and Joint Medical Stores. Through partnerships, the private provider provides quarterly or bi-annual report to the supervisory team and this contributes to the process of organizing, collecting health demographic data which the government can base on for planning and budgeting purposes.

The District Health Officer (DHO) and health inspectors visit this facility whenever it is deemed necessary. This enables the district health office to make comprehensive reports about health status in the district as it is a requirement by the Ministry of Health. The report is merged with that from public facilities to enable proper budgeting for the health sector.

"We have monthly visits from local government, medical access, ministry of health, Resident District commissioner (RDC) to check on service delivery and ensure use of the supplies" (Source: Interview with Hospital Finance officer, January 2017)

This hospital is supported by the government to deliver specific healthcare packages as stipulated in the partnership. These packages include ART drugs and HIV/AIDS care, immunization, maternal child health, anti-malarial treatment, and malaria control programs including provision of free mosquito nets to community members and outreach programs. This health facility gets PHC funding from the government of 62 million shillings $(\$ 16,756)^{1}$ annually to facilitate delivery of the health packages to the patients either free or on a subsidized costs. This partnership has saved patients from incurring high costs in purely private health facilities offering same services.

\section{Source of funding and other forms of support to RMH}

Our study found out that the hospital was running a budget of 5 billion in the financial year 2016/2017 to meet

${ }^{1} \$ 1=3700$ Uganda shillings (exchange rate) 
administrative expenses, utilities, outreaches, paying workers and buying drugs and medical equipment. From the interviews with the finance officer and the medical director, RMH gets support from the government though primary health care fund (PHC) of 62 million annually $(\$ 16,756)$. The main source of funding is the user fees from the clients who seek services at this hospital. The hospital also gets other funding (outside the partnership) and supplies from the government and local government. For example the government of Uganda supported the hospital with maama ${ }^{2}$ kits worth 39 million $(\$ 10,540)$ in January 2017 to help mothers during the process of giving birth.

RMH received other support from the government other than the support specified in the partnership. Between 2015 and 2016, the hospital received a range of support including a CD4 count machine from Mbarara district local government; equipment for the theatre, laboratory reagents, oxygen, mosquito nets, fridge to safely store drugs, bed and mattresses from the central government; and presidential anti-malarial drugs supplied annually by Joint Medical Stores (JMS).

The hospital also benefits from the sub-seconded staff paid by the government. However, based on the government salary scale, it pays less compared to other hospital staff and the hospital tops up to bring the salary to the breast of other staff at RMH. This kind of support has supported the hospital left and right and enabled it to deliver services to Ugandans. What is interesting for this study is extra support (beyond the specified benefits in the partnership) given to private providers of health services in Uganda, in this case RMH. In addition, the government gives training for example on nutrition and gives support supervisions through the office of DHO. The principal-agent theory applicability here is that the government has in a partnership arrangement has helped the PPP facilities through training and support supervision through the DHO, provision of some equipment and drugs all of which are its mandate in the PPP agreement (Lane, 2003). Whereas one can see the low PHC funding given to this hospital (62 million annually $=\$ 16,756$ ), it comes with numerous benefits mentioned above. These benefits are a result of the trustworthiness created in the process of partnering with the government by offering quality care, right use of equipment and other supplies and proper accountability of funds and supplies given to this facility.

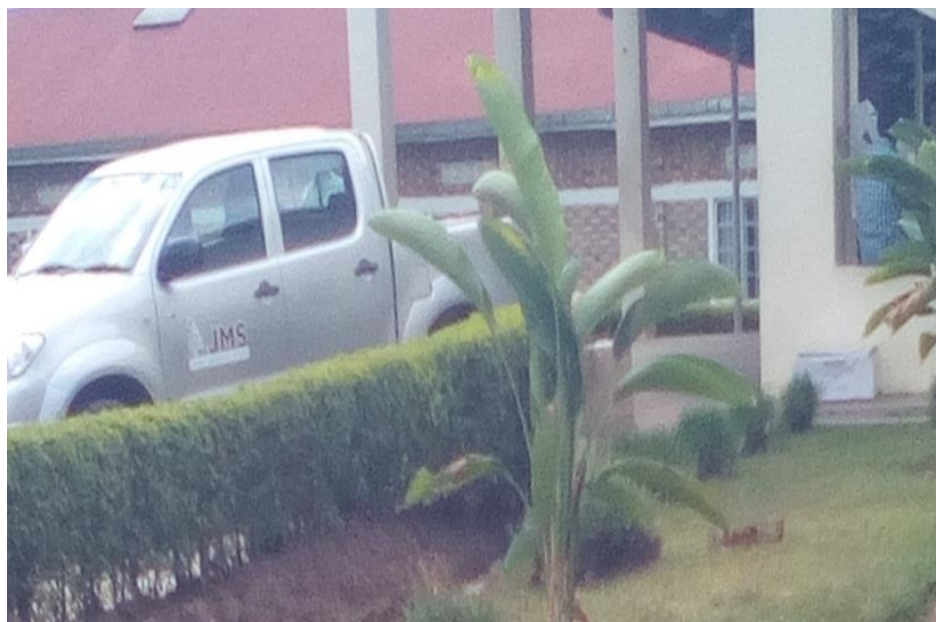

Source: Field data, January 2017

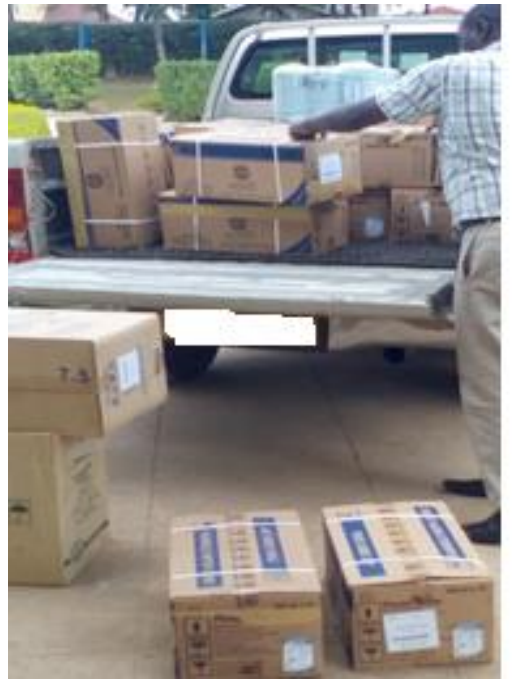

Source: Field data, January 2017

"The no. plate covered due to ethical reasons"

Trustworthiness has not only attracted benefits from the government, but also non-governmental organizations at national and international levels. Uganda Protestant Medical Bureau (UPMB) is one of the national non-governmental organization this hospital has patterned with. Support to RMH has been in various forms including lobbying the government to increase funding to the private sector. Others include accrediting and licensing health units under the Church of Uganda after registering with the ministry of health, updating the ministry on access and availability of supplies, training staff in short course programs, supporting the health coordinators (directly and indirectly) in supervising the health units, training health management committees, and the bureau is also consulting by the

\footnotetext{
${ }^{2}$ A package containing items (sharp instruments, cotton, gloves) that a pregnant woman uses during the process of giving birth
} 
government before extending any support to determine where the support should go.

Having registered with UPMB, RMH benefits from successful project proposals written by the bureau. The hospital has also benefited from expertise from UPMB by supporting short contract employed staff and paying such staff fully although the recent contract ended in February 2017, malaria control program supported by Ankole diocese and voucher scheme (system) under Marie stopes international.

Other partners supporting RMH included: Christian Blindment Mission (CBM) a fund that supports eye and Organized Useful Rehabilitation Services (OURS) departments, International Federation (IF) supporting OURS, Seeing Is Believing supporting eye department, Light for the World, Lillian Fund (LF) supporting OURS and GMS gets funding mostly from user fees USAID and PHC.

The hospital has benefited from generous individuals, a notable example was Prof. Kitya David a neurosurgeon who worked on 93 case that required brain operation. These operations were free and the credit was to the hospital for making such generous friends that offered free services.

In addition to generous individuals, the hospital itself is generous to "unable patients" who cannot raise the amount to access services at this facility. RMH set aside 46 million shillings $(\$ 12,432)$ to support such clients. Clients are assessed for eligibility to benefit from these funds. Our study observed that most of the clients in this category are those seeking services that involve operation as the cost is relatively higher. For example, the cost of operating an eye is 230,000 shillings (\$62) and both eyes 350,000 shillings (\$95). Some patients come when they are not prepared and are surprised by the cost of an operation. Such patients are not eligible to benefit from this fund.

"230,000 Uganda shillings (\$62) is a lot of money, I did not know that this much charged, I would have come prepared to meet the cost, however it is too much that I can't afford it. If this cost can be reduced then I would be able to get the services I have come for at this hospital" (A Patient narrated during an interview, January 2017).

Services offered in OURS department required a patient to pay 7,000 (\$2) shillings per day for accommodation, food and medicine.

\section{Enablers of service delivery at RMH}

The hospital being a faith-based facility, the diocesan health board supervises its operation through the office of the diocesan health officer; the church also participates in strategies to raise funds for example donors and linking the hospital with the outside world. This office supervises other health institutions under the church in Ankole diocese. The hospital also has hospital management team which responsible for policy making and overall supervision of the hospital.

The hospital is among the projects that the church runs, with many other health centres under its supervision and control under the office of the diocesan health coordinator. With its mission "Continuing Christ's Mission" it contributes directly to the running of other church activities and subscribes 30 million Uganda shillings $(\$ 8,108)$ annually. The Mission of Christ is promoting life both physical and spiritual, the hospital's mission in terms of providing quality healthcare to God's people. The hospital pays this money in affordable installments or at times as a whole, although at times when the hospital is unable to pay this money, the hospital administration finds it easy to discuss and agree with the church to waive off the balance to enable the hospital run efficiently. Our study noted that this was not the case with other faith-based facilities under the Catholic and Islamic much as they are religious based projects.

RMH is engaged in corporate social responsibility through "giving to back communities" ${ }^{3}$ they serve. The hospital's scope of operation is beyond the western region. In our interaction with respondents during interviews, we found that patients come from as far as Kibale, Masaka, Sembabule among other districts beyond the western region. The free services that they offer have widened their level of operation and made the hospital known beyond regional boarders. For example, last year during the free surgery week, 500 patients received free hearing gargets. This event is in the hospital's annual budget; and covers a lot of things beyond surgery (Office of Finance department RHM, 2017).

The hospital capitalized on the outreach as a form of advertising the quality of their services and to let the public know about the services it delivers in terms of quality and coverage. The services offered through hybrid modes of outreaches and special days like surgery week makes patients feel the touching bit of the hospital in service delivery. In other private facilities including Holy innocents Hospital, advertising and making the public aware of existence of a facility has taken a form of a marathon and mobilizing funding by selling the coupons/tickets to runners. For example, a catholic-church aided hospital, Nkozi that started in 1942 has been on a campaign to mobilize money to construct a 2.8

\footnotetext{
${ }^{3}$ Giving back to the community means rewarding/feeling proud of the community the hospital associates with. This is done through giving free services on specific days/outreaches.
} 
billion shillings $(\$ 756,757)$ emergency ward to be able to handle the overwhelming accident cases that are common on the Masaka- Kampala high way (Lukwago, 2017). The marathon was to fundraise for this cause and attracted high profile politicians including the Speaker of Uganda's $10^{\text {th }}$ Parliament Right Honorable Rebecca Kadaaga who contributed 10 million, leader of Opposition Honorable Winne Kiiza among other legislators (Lukwago, 2017). In a way of advertising and funding the hospital, the Bishop of Masaka Diocese Bishop John Baptist Kaggwa requested the government to continue supporting development projects of faith-based hospitals.

The RMH accounting system has enabled it to attract more partners. The Finance officer of RMH explained how each funder has a separate file for accountability purposes.

"We have kept in good books of PHC by receiving funds because we account for PHC funds separately from our internally generated funds. We file the report for PHC funding annually to the district auditor. RHM has no issues regarding accounting for these funds with the auditor”. (Interview: RMH finance officer, 2017).

The hospital treasures its human resource, employs an approximate of 100 workers and motivates them to work hard to offer high quality health services. According to the finance department at RHM, the workers at this hospital are paid by $22^{\text {nd }}$ of every month. This has motivated them and had enable the hospital to maintain it workers with a low rate of labor turnover of less than $10 \%$.

"Those who leave have either retired or gone for further studies, promotion, and other personal reasons. But these are not many" (Interview with RMH Executive Director, 2017).

RMH is a teaching campus for Bishop Stuart University (BSU) nursing programmes. The students at this centre conduct their practical lecture on ward at this hospital. The eye department at this hospital being one of the referral centres in the Western region for most eye complication attract masters' in medicine and surgery students specializing in eye care do some of their practical courses including internship at RMH. This was found to be an additional human resource to the hospital and has helped the hospital in delivering health services. Our study at this hospital was in agreement to other studies hospitals that associated existence of a strong hospital near/with a health training centre for example Mbarara Regional Referral Hospital next to Mbarara University of Science and Technology, Kampala International University (western campus) next to Kampala International teaching hospital in Ishaaka-Bushenyi.

\section{Challenges Faced by RMH as a PPP facility}

No ambulance is owned by RMH. In an interview with Executive Director (ED) of the hospital, he explained that only a van is owned.

"The van has no lifesaving equipment like an ambulance, losing life is likely using a van. Driving a van is like driving an individual car to seek services at a referral central, no hooting in order to clear way as critically ill patients go for emergency treatment" (Field data-Interview with ED-RMH January 2017).

Although no mortality case was documented during the study, absence of an ambulance risks life of critically ill patients at this hospital.

Giving services on debts: some clients seek services when they are not ready to pay but promise to pay afterwards. Our study noted that some clients close to the church do not pay for the health services in time much as others respond. Others that get services on credit and default, they are not tracked and the hospital is on the losing end. The reasons for offering services on credit are based on the mission for this facility "Continuing Christ's Mission" which our study interpreted as "saving life, spiritual support and helping the needy". In other facilities, it is not a common practice especially private for profit facilities due to the fear for defaulters.

Much as the hospital has one of the best theatres for eye related complications, our study also documented that RMH had no x-ray machine; health complications that required scanning services had to seek such elsewhere and come with results. This makes the process of seeking care quite difficult as clients move to the facility knowing that it has all the equipment to have the client attended to. The clients end up incurring extra costs including transport costs to look for $\mathrm{x}$-ray/scanning services.

Some donors funding contract end/leave/withheld finance. In an interview with both diocesan health officer and Executive Director, our study found that much as the hospital gets funding from the government, it is not enough to support service delivery. The hospital partners with other agencies including non-governmental organizations whose funding terms are tricky, unpredictable and one cannot know how long it last. Some of them end the contracts prematurely, other withdraw funding and others leave without any notice.

"We sign Memoranda of Understanding (MOUs) but some partners do bleach them" (Interview with Diocesan Health Officer, January 2017).

This affects service delivery especially in the specific departments that they support. 


\section{Conclusions and Recommendations}

This study concluded that different forms of support to private providers in health under the partnership arrangement have enabled them to adequately deliver services to the clients and decongest the public facilities. The government and non-governmental organizations find the existence of private partners as an opportunity to achieve their goals for example universal health coverage, reducing mortality and morbidity burden. The hybrid modes (outreaches, special days of care organized annually) of service delivery in private partner facility have lowered the cost of seeking health care and can be adopted by other facilities to improve health outcomes. The support supervision has kept the facility moving in the right direction. Supporting "un able" patients to seek health services at RMH is a good practice since it is a faith-based facility. Sub seconded staff from UPMB and the government played a significant role in service delivery and was appreciated by the hospital administration, now that the contract expired for both, our study recommends renewal to help the hospital keep the pace.

The private partners have infrastructure in place to enable it to deliver services, what is lacking an enabling environment in terms of adequate funding based on what is provided, equipment like X-rays machines, ambulances, and more meaningful MOUs. Our study concluded that little support has focused on subsidizing cost for eye operation which was at 230,000 for one eye and 350,000 shillings for both eyes. This has hindered service delivery especially for clients seeking such care. Fund-raising platforms have not been explored and the hospital need to learn from others that have organized marathons to raise funds for supporting particular health package/s. We recommended that the government and non-governmental agencies devote more funds to support the hospital through sub-seconded staff, medicine, securing an ambulance to enable it subsidize services especially eye treatment.

\section{Disclosure statement}

No potential conflict of interest was reported by the authors.

\section{Notes on the contributor}

Justus Asasira (MA), completed Masters of Arts program in 2017 at Mbarara University of Science and Technology in the Faculty of Interdisciplinary Studies (FIS). His research focuses on health systems and capacities in Uganda. He is an Assistant Lecturer in the Department of Community Engagement and Service Learning in Faculty of Interdisciplinary Studies.

Frank Ahimbisibwe (PhD) is a Senior Lecturer in the Department of Planning and Governance, Faculty of Interdisciplinary Training and Research at Mbarara University of Science and Technology. His research focuses on human security in Uganda.

I would like to thank Dr. Rogers Bariyo (Senior Lecturer-Mbarara University of Science and Technology) who supervised this research project as an academic advisor.

\section{References}

Bowling A., Rowe G., \& Lambert N. (2012). The measurement of patients expectations for health care: a review and psychometric testing of a measure of patients expectations. Health Technol Assess. https://doi.org/10.3310/hta16300

District Health Officer. (2016). Pre-visit Discussion in DHO's office with the Author.

Kamwesiga, J. (2011). Community and Home Based Rehabilitation Course: Uganda's Healthcare System

Lane, M., \& Gardiner, J. (2003). Risk management and insurance Issues in Public-Private Partnerships-A Review of Key issues. European construction institute

Lukwago, J. (2017). MPs join Nkozi hospital charity drive. The New Vision, June 19, 2017, pg.6

Mbarara District Local Government. (2015), Second District Development Plan 2015/2016-2019/2020; A Well Planned, Modern and Prosperous District within 30 years, Mbarara, Mbarara District Local Government.

Ministry of Health Uganda. (2010). The Second National Health Policy: Promoting People's Health to Enhance Socio-Economic Development, MoH, Kampala.

Ministry of Health. (2009/2010-2011/2012). National Healthcare Waster Management Plan, Prepared by National Health Management Technical Working Group 2011/2012.

Sajid, S. (2007). Quality of health care on absolutely necessity for public satisfaction. Department of Vascular Surgery Royal Free Hospital, London, U.K

Tateke, T., Woldie, M., \& Ololo, S. (2012). Determinants of patient satisfaction with outpatient health services at public and private hospitals in Addis Ababa, Ethiopia. African Journal Primary Health Care. https://doi.org/10.4102/phcfm.v4i1.384 
The Medical Transparency Alliance. (2014). Client Satisfaction with Services in Uganda's Public Health Facilities, Kampala, MeTA, Uganda National Health Consumers organization (UNHCO).

The New Vision, May 1, 2017, pg.15. Free medical outreach excite Omoro county residents.

Uganda Parliamentary Committee on Health. (2012). A Report to the Parliamentary Committee on the Ministerial Policy Statement for the Health Sector for the financial year 2012/2013, Kampala, Parliament of the Republic of Uganda.

\section{Copyrights}

Copyright for this article is retained by the author(s), with first publication rights granted to the journal.

This is an open-access article distributed under the terms and conditions of the Creative Commons Attribution license which permits unrestricted use, distribution, and reproduction in any medium, provided the original work is properly cited. 